\title{
Less soft tissue release in total knee arthroplasty for anteromedial compared to posteromedial knee osteoarthritis
}

\author{
Georg Matziolis ${ }^{1,4} \odot \cdot$ Benjamin Jacob ${ }^{1} \cdot$ Henk Eijer $^{2} \cdot$ Rüdiger von Eisenhart-Rothe $^{3,4} \cdot$ Nadja Jacob $^{1}$
}

Received: 10 May 2021 / Accepted: 12 November 2021 / Published online: 17 January 2022

(c) The Author(s) 2022

\begin{abstract}
In total knee arthroplasty (TKA), the aim of achieving a mechanically straight leg axis as well as symmetrical and equally wide gaps has become established as the gold standard in terms of surgical technique. In contrast to TKA unicompartmental knee arthroplasty (UKA) is performed in anteromedial osteoarthritis (AMOA) and does not normally require releases. This raises the hypothesis whether the type of osteoarthritis (AMOA vs. posteromedial osteoarthritis (PMOA)) determines the requirement for soft tissue releases in TKA.

In this retrospective study, 114 patients with medial osteoarthritis of the knee who had been treated with a navigated total knee replacement were consecutively included. On the basis of the preoperative lateral radiographs, the patients were divided into two groups: AMOA and PMOA. The incidence and the extent of releases performed were recorded using the navigation records.

Patient-specific data (gender, age) did not differ between the groups (NS). Knees with AMOA presented an overall varus alignment of $5.3 \pm 3.5^{\circ}$, knees with PMOA $8.0 \pm 4.0^{\circ}(p<0.001)$. 30 cases $(44 \%)$ had to be released in the AMOA group, compared with 33 cases $(72 \%)$ in the PMOA group $(p=0.004)$. In the case of medial release, the extension gap increased $3.3 \pm 2.4 \mathrm{~mm}$ in the AMOA compared to $5.3 \pm 3.7 \mathrm{~mm}$ in the PMOA group $(p=0.006)$. The medial flexion gap was released $2.2 \pm 2.6 \mathrm{~mm}$ in the AMOA and $2.9 \pm 3.0 \mathrm{~mm}$ in the PMOA group $(p=0.008)$.

To achieve a neutral mechanical alignment, a release has to be performed due to asymmetry of the extension gap more often if PMOA is present than in AMOA. Surgeons should be prepared to perform more frequent and extensive medial releases in PMOA. Higher constrained implants should be available in case of unintended over release in PMOA.
\end{abstract}

Keywords Total knee arthroplasty $\cdot$ Soft tissue release $\cdot$ Extension gap $\cdot$ Anteromedial osteoarthritis $\cdot$ Posteromedial osteoarthritis

Georg Matziolis

g.matziolis@waldkliniken-eisenberg.de

1 University Hospital Jena, Campus Eisenberg, Orthopaedic Department, Klosterlausnitzer Str. 81, 07607 Eisenberg, Germany

2 Department of Orthopaedic Surgery, Spital Emmental, Burgdorf, Switzerland

3 Department of Orthopedics and Sports Orthopedics, Klinikum rechts der Isar, Technische Universität München, Munich, Germany

4 Endoprosthetics Committee of the German Knee Society (DKG), Munich, Germany

\section{Introduction}

The number of knee replacement implantations being performed is constantly increasing throughout the world, due to the good functional results and the excellent implant survival.

The aim of achieving a mechanically straight leg axis as well as symmetrical and equally wide gaps has become established as the gold standard in terms of a surgical method [1-3]. Various different surgical techniques are available to achieve this goal (e.g. measured resection, balance gap, extension gap first technique). The size of the gaps and also the symmetry of the flexion gap can be influenced by implant size and positioning (so-called bone gap management). In contrast to this, when implanting a total knee replacement in neutral mechanical alignment, releases are 
necessary for the construction of a symmetrical extension gap in $50-80 \%$ of the cases, regardless of the surgical technique $[4,5]$.

A preoperative prognosis of the need for soft tissue release enables an estimation of the degree of difficulty of the operation, the duration of the operation and the need for semi-constrained implants.

The extent of preoperative coronal malalignment correlates with the asymmetry of the extension gap and thus with the need for releases [6]. Alongside this parameter, the entity of the osteoarthritis may have an influence on intraoperative releases. For example, with respect to the indication for sledge prostheses (UKA), anteromedial osteoarthritis (AMOA) is described as an entity that should refrain releases [7-9]. It is therefore plausible that AMOA also has a lower probability of requiring releases than posteromedial osteoarthritis (PMOA) when implanting a total knee replacement.

The objective of the present study was therefore to determine whether the localisation of the tibial cartilage defect (anteromedial vs. posteromedial) has an influence on the need for intraoperative releases.

\section{Methods}

In this retrospective study, 114 consecutive patients with medial osteoarthritis of the knee were consecutively included. Inclusion criteria were a grade IV osteoarthritis according to Kellgren of the medial compartment and at least one of the following contraindications for a medial UKA: lateral osteoarthritis, patellofemoral osteoarthritis centrally or laterally, patellar maltracking, extension deficit $>10^{\circ}$, clinically insufficient anterior cruciate ligament, PMOA [10-12]. There were no exclusion criteria. All patients were treated with a navigated total knee replacement (e.motion PS Pro using the Orthopilot 4.2, Bbraun, Tuttlingen, Germany).

The study was approved by the local ethics committee (2021-2144-Daten).
Fig. 1 Typical anteromedial (AMOA) and posteromedial (PMOA) osteoarthritis. In the AMOA the posterior aspect of the tibia has intact cartilage without local radiological signs of osteoarthritis (arrows). In the PMOA these signs reach the posterior aspect of the tibia (arrows) which points out a pathological joint kinematics
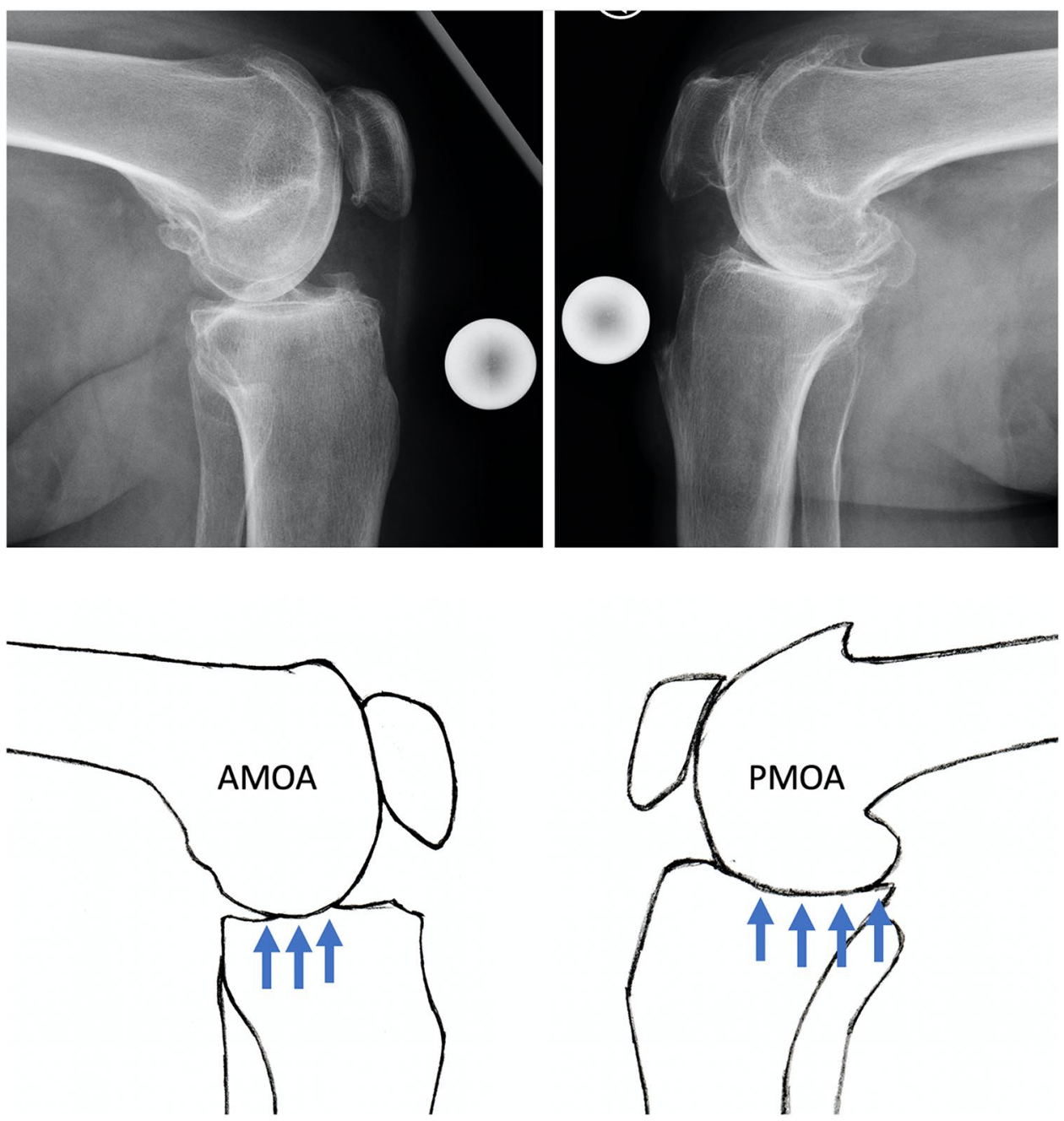
On the basis of the preoperative lateral radiographs, the patients were divided into two groups: AMOA and PMOA. The distinguishing criterion was the localisation of the typical radiological signs of osteoarthritis on the tibia (anterior vs. posterior) [13]. These included narrowing of the joint gap, sclerosis, osteophytes and subchondral bone cysts (Fig. 1). At least one of the four criteria had to apply to the posteromedial edge of the tibia to classify the osteoarthritis as PMOA. All other joints were allocated to the AMOA group.

All operations were performed according to a navigated extension gap first technique. An anatomical measured resection of the tibia was performed perpendicular to the mechanical tibial axis. After the removal of osteophytes, the joint was stretched open in extension and flexion using a ligament tensor and the resulting gaps were recorded in the system. If necessary, a release of the extension gap was performed up to symmetry in mechanically neutral alignment of the whole leg. A maximum asymmetry of $2^{\circ}$ was tolerated here. If no release was necessary, the femoral component was selected in an appropriate size, translated and rotated in such a way that a symmetrical and $2 \mathrm{~mm}$ larger flexion than the extension gap resulted. If a release was performed, the flexion and extension gap were recorded again and, if necessary, further releases were performed up to the abovementioned extension gap symmetry.

The incidence and the extent of releases performed were recorded using the navigation records. Here, the absolute size of the medial and lateral flexion and extension gap was documented in $\mathrm{mm}$.

Age, sex, preoperative coronal malalignment and extension deficit were taken from the navigation record.

\section{Statistics}

Mean values and standard deviations of the gaps, of patient age and of the preoperative extension deficit were calculated. Group differences were tested for using a $t$ test for unmatched samples. Differences in the incidence of releases were analysed with the chi-squared test. All tests were performed at a significance level of 0.05 .

Table 1 Patient demographics, preoperative flexion contracture and leg axis

\begin{tabular}{lllr}
\hline & AMOA & PMOA & $p$ value \\
\hline Gender & $32 \mathrm{~m}, 35 \mathrm{f}$ & $23 \mathrm{~m}, 24 \mathrm{f}$ & 0.902 \\
Age (years) & $70.3 \pm 15.3$ & $66.6 \pm 12.2$ & 0.169 \\
Flexion contracture $\left(^{\circ}\right)$ & $-1.0 \pm 6.4$ & $1.6 \pm 6.6$ & 0.043 \\
Pre-OP varus $\left({ }^{\circ}\right)$ & $5.3 \pm 3.5$ & $8.0 \pm 4.0$ & $<0.001$ \\
\hline
\end{tabular}

\section{Results}

114 knees (114 patients) were consecutively included in this retrospective study. Of these, $68(60 \%)$ were classified to be AMOA and 46 (40\%) to be PMOA. Patient-specific data (gender, age) did not differ between the groups (NS, Table 1). Knees with AMOA presented with a mean hyperextension of $1.0 \pm 6.4^{\circ}$ and an overall varus alignment of $5.3 \pm 3.5^{\circ}$. These values differed significantly from knees with PMOA, which had a flexion contracture of $1.6 \pm 6.6^{\circ}$ at an overall varus alignment of $8.0 \pm 4.0^{\circ}$. Even if the differences were small $\left(2.6^{\circ}\right.$ more flexion contracture and $2.7^{\circ}$ more varus), PMOA knees presented a more severe varus osteoarthritis than the AMOA knees ( $p=0.043$ and $p<0.001$, respectively).

30 cases (44\%) had to be released in the AMOA group, compared with 33 cases $(72 \%)$ in the PMOA group (Table 2). The difference was statistically significant $(p=0.004)$.

In the case of medial release, the extension gap increased $3.3 \pm 2.4 \mathrm{~mm}$ in the AMOA compared to $5.3 \pm 3.7 \mathrm{~mm}$ in the PMOA group (Table $3, p=0.006$ ). The medial flexion gap was released $2.2 \pm 2.6 \mathrm{~mm}$ in the AMOA and $2.9 \pm 3.0 \mathrm{~mm}$ in the PMOA group $(p=0.008)$.

Despite maximum medial releases in the PMOA group of $14 \mathrm{~mm}$ (extension gap) and $9.9 \mathrm{~mm}$ (flexion gap) no case of over release was documented.

Table 2 Soft tissue release was performed in $44 \%$ of the AMOA cases and in $72 \%$ of the PMOA cases $(p=0.004)$

\begin{tabular}{lll}
\hline & AMOA & PMOA \\
\hline Release & 30 & 33 \\
No release & 38 & 13 \\
\hline
\end{tabular}

Table 3 Extend of soft tissue release, mean value, standard deviation and maximum release

\begin{tabular}{llll}
\hline & AMOA $(\mathrm{mm})$ & PMOA $(\mathrm{mm})$ & $p$ value \\
\hline Medial extension gap & $3.3 \pm 2.4$ & $5.3 \pm 3.7$ & 0.006 \\
& $\max .8 .5$ & $\max .14 .0$ & \\
Lateral extension gap & $0.4 \pm 1.1$ & $1.6 \pm 2.2$ & 0.008 \\
& $\max .2 .7$ & $\max .7 .1$ & \\
Medial flexion gap & $2.2 \pm 2.6$ & $2.9 \pm 3.0$ & 0.146 \\
& $\max .9 .9$ & $\max .9 .9$ & \\
Lateral flexion gap & $0.3 \pm 1.4$ & $0.1 \pm 1.3$ & 0.279 \\
& $\max .2 .6$ & $\max .3 .9$ & \\
\hline
\end{tabular}

Only cases where a release was performed were included in this calculation 


\section{Discussion}

The main result of the present study is that a release has to be performed due to asymmetry of the extension gap more often if PMOA is present than in AMOA. In the case of medial release, it is significantly more extensive in PMOA compared to AMOA.

Anteromedial osteoarthritis typically occurs when medially pivoting and laterally translating joint kinematics are present in the case of intact cruciate ligaments [14]. It is thus an indirect sign of intact joint kinematics. This may also explain why the treatment of AMOA with a total knee replacement results in significantly better clinical outcomes than the treatment of PMOA $[15,16]$. In the latter, pathological joint kinematics lead to a posterior translation of the medial femoral condyle [17, 18]. As a consequence, a shortening in particular of the posteromedial soft tissue structures may occur, which stabilise the medial extension gap. It is questioned whether ligament structures can indeed contract and thus become shorter, or whether this is exclusively possible for capsule tissue and ligaments can at most elongate $[19,20]$. A contracture of the posteromedial capsule would sufficiently explain the shortening of the medial extension gap observed in the present study [21,22].

In contrast to PMOA, AMOA is considered an indication criterion for medial UKA. Surprisingly, however, releases were performed in this study in $44 \%$ of the knees in the AMOA group, although UKA is normally performed without any release [23, 24]. This may be a result of the fact that all TKAs were performed in a mechanically neutral axis in this study. In contrast to this, UKAs are implanted according to the specified ligament tension, so that an undercorrection of up to $4^{\circ}$ is optimal and up to $7^{\circ}$ is tolerable [25-27]. This ligament-guided surgical technique makes releases largely unnecessary in UKA. With kinematic alignment (KA), similarly to UKA, TKA also follows the concept of undercorrection of the leg axis to a pre-arthritic level [28, 29]. A meta-analysis has shown that this significantly reduces the need for releases in KA, compared with strict mechanical alignment (MA) [30].

The main limitation of the present study is the technique of differentiation between AMOA and PMOA. The localisation of the osteoarthritis was not documented intraoperatively using the resected tibial tissue, so that, as a result of the retrospective study design, it was only possible to use the preoperative radiographs for group allocation. This technique is recommended for establishing the indication for a medial sledge prosthesis and is applied in routine clinical practice [13]. Nevertheless, it has not been validated and requires a correct lateral projection plane.

The ability to restore a neutral mechanical alignment before any bone resection has been shown to be an excellent predictor of collateral ligament release (sensitivity of $100 \%$, specificity of $98 \%$ ). But such measurements can only be performed intraoperatively and with the use of a navigation system $[31,32]$.

In conclusion, if posteromedial osteoarthritis of the knee is diagnosed in the preoperative lateral radiograph, it can be expected that intraoperative releases will be required with the aim of neutral mechanical alignment. These releases will have be more extensive than in AMOA, so that surgeons should be prepared for that. In such cases, higher constrained implants should be available in case of unintended overrelease in PMOA.

Funding Open Access funding enabled and organized by Projekt DEAL. There is no funding source.

\section{Declarations}

Conflict of interest The authors declare that they have no conflict of interest.

Ethical approval The study was approved by the local ethics committee (2021-2144-Daten).

Informed consent Not applicable according to the ethics approval (retrospective data analysis with anonymization).

Open Access This article is licensed under a Creative Commons Attribution 4.0 International License, which permits use, sharing, adaptation, distribution and reproduction in any medium or format, as long as you give appropriate credit to the original author(s) and the source, provide a link to the Creative Commons licence, and indicate if changes were made. The images or other third party material in this article are included in the article's Creative Commons licence, unless indicated otherwise in a credit line to the material. If material is not included in the article's Creative Commons licence and your intended use is not permitted by statutory regulation or exceeds the permitted use, you will need to obtain permission directly from the copyright holder. To view a copy of this licence, visit http://creativecommons.org/licenses/by/4.0/.

\section{References}

1. Karachalios T, Sarangi PP, Newman JH (1994) Severe varus and valgus deformities treated by total knee arthroplasty. J Bone Joint Surg Br 76:938-942

2. Winemaker MJ (2002) Perfect balance in total knee arthroplasty: the elusive compromise. J Arthroplasty 17:2-10. https://doi.org/ 10.1054/arth.2002.29321

3. Griffin FM, Insall JN, Scuderi GR (2000) Accuracy of soft tissue balancing in total knee arthroplasty. J Arthroplasty 15:970-973. https://doi.org/10.1054/arth.2000.6503

4. Engh GA (2003) The difficult knee: severe varus and valgus. Clin Orthop Relat Res 416:58-63. https://doi.org/10.1097/01. blo.0000092987.12414.fc

5. Whiteside LA, Saeki K, Mihalko WM (2000) Functional medical ligament balancing in total knee arthroplasty. Clin Orthop Relat Res. https://doi.org/10.1097/00003086-200011000-00007 
6. Matziolis G, Matziolis D, Perka C (2012) Pre-operative frontal plane malalignment predicts the extension gap asymmetry in knee osteoarthritis. Int Orthop (SICOT) 36:79-82. https://doi.org/10. 1007/s00264-011-1294-7

7. White SH, Ludkowski PF, Goodfellow JW (1991) Anteromedial osteoarthritis of the knee. J Bone Joint Surg Br 73:582-586. https://doi.org/10.1302/0301-620X.73B4.2071640

8. Pandit H, Hamilton TW, Jenkins C et al (2015) The clinical outcome of minimally invasive Phase 3 Oxford unicompartmental knee arthroplasty: a 15-year follow-up of 1000 UKAs. Bone Joint J 97-B:1493-1500

9. Goodfellow JW, Kershaw CJ, Benson MK, O’Connor JJ (1988) The Oxford Knee for unicompartmental osteoarthritis. The first 103 cases. J Bone Joint Surg Br 70:692-701. https://doi.org/10. 1302/0301-620X.70B5.3192563

10. Kozinn SC, Scott R (1989) Unicondylar knee arthroplasty. J Bone Joint Surg Am 71:145-150

11. Vince KG, Cyran LT (2004) Unicompartmental knee arthroplasty: new indications, more complications? J Arthroplasty 19:9-16. https://doi.org/10.1016/j.arth.2004.02.022

12. Berend KR, Berend ME, Dalury DF et al (2015) Consensus statement on indications and contraindications for medial unicompartmental knee arthroplasty. J Surg Orthop Adv 24:252-256

13. Keyes GW, Carr AJ, Miller RK, Goodfellow JW (1992) The radiographic classification of medial gonarthrosis. Correlation with operation methods in 200 knees. Acta Orthop Scand 63:497-501. https://doi.org/10.3109/17453679209154722

14. Price AJ, Rees JL, Beard DJ et al (2004) Sagittal plane kinematics of a mobile-bearing unicompartmental knee arthroplasty at 10 years. J Arthroplasty 19:590-597. https://doi.org/10.1016/j.arth. 2003.12.082

15. Howell RE, Lombardi AV, Crilly R et al (2015) Unicompartmental knee arthroplasty: does a selection bias exist? J Arthroplasty 30:1740-1742. https://doi.org/10.1016/j.arth.2015.05.010

16. Jessing IR, Mikkelsen M, Gromov K et al (2020) Patients with anteromedial osteoarthritis achieve the greatest improvement in patient reported outcome after total knee arthroplasty. Arch Orthop Trauma Surg 140:517-525. https://doi.org/10.1007/ s00402-020-03337-2

17. Raju PK, Kini SG, Verma A (2012) Wear patterns of tibiofemoral articulation in osteoarthritic knees: analysis and review of literature. Arch Orthop Trauma Surg 132:1267-1271. https://doi.org/ 10.1007/s00402-012-1547-y

18. Roberts BC, Solomon LB, Mercer G et al (2018) Relationships between in vivo dynamic knee joint loading, static alignment and tibial subchondral bone microarchitecture in end-stage knee osteoarthritis. Osteoarthritis Cartilage 26:547-556. https://doi.org/10. 1016/j.joca.2018.01.014

19. Okamoto S, Okazaki K, Mitsuyasu H et al (2013) Lateral soft tissue laxity increases but medial laxity does not contract with varus deformity in total knee arthroplasty. Clin Orthop Relat Res 471:1334-1342. https://doi.org/10.1007/s11999-012-2745-1

20. Ushio T, Mizu-uchi H, Okazaki K et al (2019) Medial soft tissue contracture does not always exist in varus osteoarthritis knees in total knee arthroplasty. Knee Surg Sports Traumatol Arthrosc 27:1642-1650. https://doi.org/10.1007/s00167-018-5276-9

21. Sasabe R, Sakamoto J, Goto K et al (2017) Effects of joint immobilization on changes in myofibroblasts and collagen in the rat knee contracture model. J Orthop Res 35:1998-2006. https://doi. org/10.1002/jor.23498

22. Kaneguchi A, Ozawa J, Kawamata S, Yamaoka K (2017) Development of arthrogenic joint contracture as a result of pathological changes in remobilized rat knees. J Orthop Res 35:1414-1423. https://doi.org/10.1002/jor.23419

23. Whiteside LA (2005) Making your next unicompartmental knee arthroplasty last: three keys to success. J Arthroplasty 20:2-3. https://doi.org/10.1016/j.arth.2005.03.029

24. Emerson RH, Head WC, Peters PC (1992) Soft-tissue balance and alignment in medial unicompartmental knee arthroplasty. J Bone Joint Surg Br 74:807-810. https://doi.org/10.1302/0301-620X. 74B6.1447238

25. Kleeblad LJ, van der List JP, Pearle AD et al (2018) Predicting the feasibility of correcting mechanical axis in large varus deformities with unicompartmental knee arthroplasty. J Arthroplasty 33:372378. https://doi.org/10.1016/j.arth.2017.09.052

26. Hernigou P, Deschamps G (2004) Alignment influences wear in the knee after medial unicompartmental arthroplasty. Clin Orthop Relat Res. https://doi.org/10.1097/01.blo.0000128285.90459.12

27. Argenson J-NA, Parratte S (2006) The unicompartmental knee: design and technical considerations in minimizing wear. Clin Orthop Relat Res 452:137-142

28. Howell SM, Howell SJ, Hull ML (2010) Assessment of the radii of the medial and lateral femoral condyles in varus and valgus knees with osteoarthritis. J Bone Joint Surg Am 92:98-104. https://doi. org/10.2106/JBJS.H.01566

29. Nedopil AJ, Singh AK, Howell SM, Hull ML (2018) Does calipered kinematically aligned TKA restore native left to right symmetry of the lower limb and improve function? J Arthroplasty 33:398-406. https://doi.org/10.1016/j.arth.2017.09.039

30. Gao Z-X, Long N-J, Zhang S-Y et al (2020) Comparison of kinematic alignment and mechanical alignment in total knee arthroplasty: a meta-analysis of randomized controlled clinical trials. Orthop Surg 12:1567-1578. https://doi.org/10.1111/os.12826

31. Hakki S, Coleman S, Saleh K et al (2009) Navigational predictors in determining the necessity for collateral ligament release in total knee replacement. J Bone Joint Surg Br 91-B:1178-1182. https:// doi.org/10.1302/0301-620X.91B9.22043

32. Saragaglia D, Chaussard C, Rubens-Duval B (2006) Navigation as a predictor of soft tissue release during 90 cases of computerassisted total knee arthroplasty. Orthopedics 29:S137-138

Publisher's Note Springer Nature remains neutral with regard to jurisdictional claims in published maps and institutional affiliations. 